\title{
FUNDAMENTAL ASPECTS OF COMMUNICATION MANAGEMENT, IN THE CASE OF PUBLIC ADMINISTRATION
}

\author{
Dorian Pocovnicu \\ Interdisciplinary Doctoral School in Marketing, "Transilvania” University of Braşov \\ dorianpocovnicu@yahoo.com
}

\begin{abstract}
Efficient communication is one the most important instruments used for the purpose of generating change inside and outside an organization. It can contribute to adjusting attitudes and the manner of approaching the present and future challenges and to changing behavioral patterns. The mission and the objectives of organizational communication are highly interrelated with organizational change and environment characteristics, in which the organization functions. The communication performed by the public administration institution outside is an institutional communication, extra-organizational, which presents the following purposes: strengthening its image, stimulating an environment of trust and affinity from the citizens (Kotler \& Lee, 2007). We are of opinion that the management of communication performed by a public administration institution features three fundamental aspects, relevant for institutional communicators when designing and managing the institutional communication: communication efficiency, communication process and the implications of the new information and communication technologies (ICT) for this process.
\end{abstract}

\section{Keywords}

communication management; efficiency of communication process; institutional communication; organizational culture; ICT; public services

\section{JEL Classification}

M31; M38

\section{Introduction}

The special part communication holds in ensuring the functionality and efficiency of the institution's activities is mainly generated by: the volume, complexity and diversity which can be estimated for the institution's objectives and its subsystems, due to the impact of the national and international environment variables; the profound changes within the dimensional and functional characteristics of the modern organization/institution; the groups and how they are designed and how they function within the organization, considering the role communication plays in spreading and amplifying the connections between the members of the groups and in consolidating the cohesion between them; the managerial activity and the structural pattern of work-time into sequences which allow for problem solving and operational solutions to be performed by specific departments.

The communication performed by the public administration institution towards the exterior is an institutional communication, extra-organizational by which the following objectives are framed: strengthening the institutional imagery; stimulating a cohesive and coherent communicational climate and maintaining a trust and sympathetic relation with specialized audiences, such as citizens and stakeholders.

Public administration institutions aim to gain, through communication, the following effects: identification - what is necessary for the institution to ensure its notoriousness 
and to have its competence acknowledged; information - the social bodies within society must be informed upon the administrative actions of the institution; achieving a social education - befits the most important part a public institution plays within society.

Communication management, at the level of public administration institutions, presents three fundamental aspects fundamental aspects, relevant for institutional communicators when designing and managing the institutional communication: communication efficiency, communication process and the implications of the new information and communication technologies (ICT) for this process.

\section{Pragmatic and relational aspects of communication efficiency, in the case of public administration institutions}

One of the most important aspects of institutional communication is efficiency or performance. In the context of a highly unstable environment, communication efficiency is capital for the common activities of an institution. Performance in institutional communication can be defined by the performance level achieved for the three communicational pillars, namely: interpersonal communication, internal communication and external communication. Its analysis presents as starting point the emphasis on the characteristics of public institutions, as organizational entities. The theories of public administration assert the fact that these types of entities are, in fact, the subject of political authority and, unlike private organizations, the level of public authority is much higher. The higher level of responsibility required by political authority presents a deeper impact upon the structure and the processes from within the public institutions.

Several features of public institutions have been emphasized as important factors in evaluating communication efficiency. These are: clarity of objectives, bureaucracy level, organizational culture and organization size (Pandey\& Garnett, 2006).

Clarity of objectives or their ambiguity represents one the most important characteristics of public institutions. Unlike the individual, the organization, and especially the public institution, presents a higher number of objectives, thus adding to the costs equation a new item, namely the absences of a clear hierarchy of the preferred means of achieving the goals. The diversity of objectives often entails a potential conflict between them. This is why the ambiguity of objectives is often associated with the presence of multiple and diverse objectives. It is within this frame that the literature converges towards the importance of the clarity characteristic when dealing with the results of a public institution. It generates direct effects upon the accuracy and the consistency of the communication between the institution and its specialized audiences. Negotiating conflicts when setting up the objectives and increasing their accuracy entails positive outcomes for key aspects of communication, such as: information dissemination, influencing attitudes, promoting awareness and persuading the audiences to act or not in a certain way.

The concept of bureaucracy can be defined as "a set of rules, regulations and procedures applied with authority which generate the need for conformity but which do not serve the originating purpose for which they have been designed” (Bozeman, 1993). A more recent definition states that it represents "a set of compulsory rules designed by management levels with a negative impact on the organization interests" (Pandey\&Kingsley, 2000). The bureaucracy within an institutional structure creates negative effects such as: diminishing the benefits for the target group and the separation within the labor process. The effects of bureaucracy on communication efficiency manifest on two directions. The first one implies that the rigid rules and procedures negatively influence the existence, emergence and the capacity of the communication channels by which information is communicated. The second one 
denotes that bureaucracy inhibits personal motivation to seek for or to provide the necessary information. Studies performed on bureaucracy and on the effects upon institutional communication have proved that excessive formality leads to diminishing the usage potential of informal channels used for identifying the useful information for an institution (Shrader, Lincoln \& Hoffman, 1989). In most cases, efficient communication means less usage of formal channels. Centralization, another trait of bureaucracy, also carries weight on communication efficiency. Thus, a high level of centralization generates a lower level of communication, a lower time and a lower level of feedback.

Even though the importance of organizational culture on the institution results is acknowledged, there are few studies to show the impact of organizational culture upon the existence and performance of public institutions. Most of the studies in this domain have focused on the analysis of the concept communicational climate. It can be defined as "the set of perceptions individuals present in connection with an organization". The domain literature focused on a series of traits, such as: trust, disclosure, credibility, accuracy and frequency of communication. Other definitions for organizational climate extend the conceptual boundaries by inserting several elements, such as: organizational structure, individual responsibility, support, rewards and sanctions, performance standards, resolving conflicts and organizational identity (Pincus \& Rayfield, 1989).

Organization size, most often defined as the number of employees, can also be responsible for communication efficiency. On one side, communication becomes difficult when dealing with big institutions or complex structures, but on the other side, the same big institutions present at their disposal resources, expertise and highly significant budgets to use within the communication process. Research has shown that there is a variable dependency between organization size and communication efficiency. Thus, big organizations present a high number of hierarchical levels and it is this additional filtering of the communication process that affects its accuracy and speed (Garnett, 1992). The size of the institution can have a positive impact on communication if it is backed up by stability and efforts to expand the communication expertise and the available resources.

\section{Communication process in public administration - key factor for an efficient management of the public institutional system}

The communication process in public administration can be considered a key factor in efficiently performing the social and economic functions of this system, responsible for implementing public policies. The quality of the informational relations between the subjects of public administration processes is determined by a set of factors, and its influence is exerted upon the entire system of the public administration organization. Moreover, the same quality impacts the informational flows within the entire system of public authority. Recent research has shown that the communication quality within the same system of public administration is influenced by using modern forms of communication promoted by the new ICT.

In the communication process, the relation public administration - citizens represents the core of the public administration act. The entities which are responsible with communication, namely the public clerk (as a sender) and the citizen (as a receiver) present clear objectives: the sender informs, persuades, guides, captures interest and must be efficient whereas the receiver is attentive, willing to understand, to capture and assimilate the information (McKnigh, 2005).

From a structural approach, the relation between public administration institutions and the citizens envisages the following aspects: the possibility of a fast and easy access to information and to the public services for the local population; improving service 
quality offered to customers; providing public services directly to the citizens and in a lesser degree through intermediaries, such as agencies or other types of clerks; ensuring a climate of trust and understanding between public administration institutions and citizens; participation of citizens in the process of local decision making and in managing the public institutions; promoting the participation and involvement of citizenry in local democracy and urban development. Modern administrations give priority to their objectives regarding citizen services development, providing quality, consistent and up-to-date information and creating the necessary tools for an active participation of any citizen in the administrative and political decisions he is affected by. Achieving these objectives especially rely on the new information and communication technologies (ICT) (Baciu, n.d.).

The public clerk plays a special part in the organization and development of the communication process inside the public administration institution, and depending on how well he promotes the communicational act one can analyses the efficiency of his/her activity and the quality of achieving the established objectives. Generally, public administration domain requires that the public clerk presents a high level of professionalism, absolute ethics, professional and private, a high level of education, physical skills and qualities.

Public institutions which use a citizen-oriented approach create the possibility for a trustworthy climate to take shape within the administrative system. This trust creates a solid ground for citizens and state authorities so that, by working together, to solve local issues. After gathering information from citizens, the local officials of an administration have the obligation to listen and to take into consideration their opinions.

During the last ten years, framing the idea that citizens must be considered as clients has become more important in the rationale and actions of public authorities (see Law 215/2001 of local public administration). Therefore, clients have the right to demand from the public suppliers services which satisfy their needs rapidly, accessible, at a low price but a high quality and also offered with politeness. This rule applies especially to the administration, as a supplier of basic public services. Performing a public service is not an isolated activity, but a part of a complex relation between administration, society and citizens, on several pillars, because it is dynamic and because administration itself is a complex organism (Androniceanu, 2002).

\section{Implications of information and communication technologies' development on the communication processes inside public administration}

Lately, more and more governments of developing countries have published ambitious proposals for reform of their own administrative systems by using new information and communication technologies (ICT). These type of proposals have been identified on the agenda of transnational organizations such as the European Union or the G7. Although these initiatives differ considerably, from a domain and implementation context point of view, they reflect, undoubtedly, the existence of a general consensus regarding the possibilities offered by the new ICT. The rising synergy between information technology and telecommunications will allow governments to become more flexible when dealing with collecting and using of information.

The new means of administration and information communication allow governments to avoid the dilemma between cost reduction and quality increase, thus creating and administrative structures which function better and cost less. More important, the new interaction channels open up the communication path between governments and citizens, paving the way towards increased transparency, higher responsibility and 
opening up governments to accessible forms of citizens' participation (Wescott, Pizarro \& Schiavo-Campo, 2000).

Within the last decade, local and national agencies, especially from developed countries, have begun to implement ICT for an increasing palette of public service. These applications focus on two objectives: achieving major improvements in reaction speed, in efficiency and public service accessibility and bringing governments closer to citizens.

The potential benefits of the new technologies for the public services provided by public administration institutions are (Dutton, 1996): cutting down administrative costs; quicker and more precise response to request and data base interrogations, including outside normal working hours; data access to all levels and structures of administration, from any location; increasing government capacity; assistance to local and national economies by facilitating the interface government - business stakeholders and an additional tool for public feedback.

ICT are not yet used on a large scale by the governments of developing countries in order to solve issues, such as: information exchange between administrative structures; documents flow until approval; digital filling up of online forms; access to public information; gathering feedback by public clerks and providing answers in due time; archiving of documents; publishing statistical results, etc. The printed form of the documents still prevails and the phone still represents the main tool used for prompt action.

\section{Conclusions}

Improving the activity and communication in public sector can be achieved, in a complementary manner, by adopting instruments which have long been used by the private sector, so that the performance of the institution's activity may increase in efficiency. Converting the improvement techniques of specific methods and technique from the private sector represents social innovation trend within public institutions. Therefore, from the point of view of communication management in public administration institutions, the clarity of objectives may be considered the equivalent of SMART acronym, used in project management, where $\mathrm{S}$ stands for specific, $\mathrm{M}$ for measurable, A for accessible, $\mathrm{R}$ for realists and $\mathrm{T}$ for time frame. This acronym is a feature of the new public management approach, namely a management based on public institution performance correlated with the established objectives.

The level of bureaucracy and organization size is two elements, considered important in evaluating the communication process of a public institution. The economic crisis has forced several public institutions to downsize personnel and to increase the tasks/employee for the remaining personnel. In such a context the bureaucratic surplus affects the efficiency communication/inter-department and communication/intra-department. A proficient solution for reducing bureaucracy and maintaining the communication efficacy at either department or institution level is represented by inter-relating the new ICT with the two elements, so that delivering the public service by the public institution is not affected. Even so, managing the new ICT is a complex process, which requires keeping in the system new public clerks with a medium and advanced level of ICT knowledge, so that performance in communication and in public service delivery does not remain a desideratum.

As for the communication process, during the last ten years, the paradigm shift in perceiving the citizens as clients has become more important in the way the public authorities think and act. Changing the procedural paradigm of public institutioncitizen communication has entailed positioning the relation citizen-institution on certain hybrid conceptual pillars, within which information, public policy benefits and 
delivered services have started to be considered as hybrid products, objectified, standardized or adapted to the specific need of target groups and audiences.

When dealing with the communication mix, the public administration institutions can benefit from using the new ICTs and the social media networks, such as promoting the institutions initiatives, informing the citizens and the potential beneficiaries of the public services, achieving a real dialogue with the citizens and improving the internal communication processes. It is on this background that we consider the following future research strands in using social media by public administration institutions: shifting from ICT to social media - change of paradigm and of concept; a more efficient interaction with the citizens - how, when and who to be in charge; a better management of crisis situations and improving the institutional imagery and brand.

\section{References}

Amalancei, B-M., Manole V., Epuran Gh. (2009), Communication Et Relations Publiques Dans L'Union Européenne, Annals of Faculty of Economics, University of Oradea, Faculty of Economics, vol. 4(1), pages 542-546, May.

Androniceanu, A. (2002), Management public, Editura Economică.

Banciu, D., Servicii de informare pentru cetăţeni în societatea informaţională, available at www.acad.ro/pro_pri/doc/st_f00.doc.

Bozeman, B. (1993), A Theory of Government "Red Tape", Journal of Public Administration Research and Theory, 3 (3).

Dutton, William H., ed. (1996), Information and Communication Technologies: Visions and Realities, Oxford University Press.

Garnett, James L. (1992), Communicating for Results in Government: A Strategic Approach for Public Managers, San Francisco: Jossey-Bass.

Kotler, P., Lee, N. (2007), Marketing in the Public Sector. A Roadmap for Improved Performance, Wharton School Publishing, New Jersey.

McKnigh, K. M. t et al. (2005), Psychology, Psychologists, and Public Policy, 1 ANN. REV. CLINICAL PSYCHOL. 557, 567.

Pandey, S. K., Kingsley, G.A. (2000), Examining Red Tape in Public and Private Organizations: Alternative Explanations from a Social Psychological Model, Journal of Public Administration Research and Theory, 10 (4).

Pandey, S.K., Garnett, J.L. (2006), Exploring Public Sector Communication Performance: Testing a Model and Drawing Implications, Public Administration Review, January - February.

Pincus, J. D., Rayfield, R.E. (1989), Organizational Communication and Job Satisfaction: A Metaresearch Perspective, in Progress in Communication Sciences, edited by Brenda Dervin and Melvin J . Voigt, Norwood, NJ, Ablex.

Shrader, C.B., Lincoln, J.R., Hoffman, A.N. (1989), The Network Structures of Organizations: Effects of Task Contingencies and Distributional Form, Human Relations, 42 (1).

Wescott, C., Pizarro, M., Schiavo-Campo, S. (2000), To Serve And To Preserve: Improving Public Administration In A Competitive World. Guidelines, Handbooks, and Manuals, Chapter XIX, Asian Development Bank. 